\title{
Torque ripple minimization of PMBLDC motor using simple boost inverter
}

\author{
V. Krishnakumar', N. Madhanakkumar ${ }^{2}$, P. Pugazhendiran $^{3}$, C. Bharathiraja ${ }^{4}$, V. Sriramkumar ${ }^{5}$ \\ ${ }^{1}$ Department of Electrical and Electronics Engineering, St. Joseph's College of Engineering, India \\ ${ }^{2}$ Mailam Engineering College, India \\ ${ }^{3}$ Department of Electrical and Electronics Engineering, IFET College of Engineering, India \\ ${ }^{4}$ SRM Institute of Science and Technology, India \\ ${ }^{5}$ Mailam Engineering College, India
}

\section{Article Info \\ Article history: \\ Received Sep 11, 2018 \\ Revised Nov 19, 2018}

Accepted May 26, 2019

\section{Keywords:}

BLDC motor

PMBLDC

Torque ripple minimization

\begin{abstract}
This paper proposes the implementation of simple boost circuit incorporated in inverter fed Brushless DC (BLDC) motor drive to boost the performance of torque. BLDC motor becoming subtle because of its performance. But the motor performance is inferior due to the voltage source inverter fed operation of BLDC motor which initiates torque ripple during commutation. Here the usage of Switched Boost Inverter (SBI) which minimizes the storage elements (passive elements), more active element and introduces shoot through mode during commutation as like Z-source inverter. The analyses of three phase switched boost inverter fed BLDC motor drive have been carried out. The performance of torque almost depends on the stator phase current of the motor. In BLDC motor during commutation interval, one phase loss its exact stator phase current hence it instigate ripple on the torque. The proposed method focuses two intentions to reduce the torque ripple. The first intension is to operate the BLDC motor at $180^{\circ}$ electrical conduction mode, second intension is to introduce the shoot through interval to boost the dc link voltage so as to maintain the stator phase current control which leads to suppress the torque ripple during commutation. The validation of the proposed SBI based BLDC motor control is demonstrated both by MATLAB/Simulink and Field programmable gate array (FPGA) controllerSPARRTAN III processor. The experimental results of the developed SBI based BLDC motor drive is working over a wide speed range with minimal torque ripple compared to the normal PWM based inverter control.
\end{abstract}

Copyright (C) 2019 Institute of Advanced Engineering and Science. All rights reserved.

\section{Corresponding Author:}

V. Krishnakumar,

Department of Electrical and Electronics Engineering,

St. Joseph's College of Engineering,

OMR, Chennai-600119, India.

Email: v_krishnakumar@ymail.com

\section{INTRODUCTION}

In recent days Brushless DC motor becoming popular because of absence of brushes. BLDC motor is used in medical instruments, space, fuel pump, actuators and robotics applications. Normal DC motor has mechanical commutator which was subjected to wear and tear. The introduction of electronic commutator (Six Step Inverter) in BLDC motor made it possible to operate in reliable manner. There are many motors inside the airplane and biomedical instruments is replaced by BLDC motor due to its superior performance like higher dynamic response, higher efficiency and has high torque to weight ratio. This paper presents a SBI which boosts the voltage in the inverter. The boost inverter uses reduced storage elements. This boost inverter is implemented in the BLDC motor drive which reduces the stator current harmonics spectrum. 
The digital speed controllers for three phase BLDC motor have been designed to operate in four quadrants. The proposed method confines the power loss and in regenerative mode the energy has been efficiently utilized [1]. The integral variable structure control (IVSC) to reduce the torque ripple in brushless DC motor has been presented. The non ideal trapezoidal back EMF waveshape and conventional current control strategy are the major concern for generation of torque ripple in BLDC motor. The current optimization mechanism has been proposed to reduce the torque ripple [2]. The hysteresis comparator for BLDC motor to achieve sensorless control for automotive fuel pump applications have been designed which senses the three phase terminal voltage and fed to the low pass filter (LPF) to supress the high switching frequency noise. The phase lags of the rotor speed have been denoted by variation in cut off frequency of LPF. The hysteresis comparator has been introduced to compensate the phase lag issues. The phase lag issues have significantly adjusted [3]. The mathematical equation of the cogging torque, unbalanced magnetic force (UMF) and back EMF to the BLDC motor has been derived to estimate the harmonics effect in PM magnetization. The experimental validation of proposed mathematical equations has been tested in hard disc drive. The uneven magnetization of PM caused due to the harmonics of back EMF, cogging torque and UMF has been improved [4]. The Bridgeless cuk converter for BLDC motor drive has been developed. The proposed converter drive operates in discontinuous inductor current mode (DICM) to enhance power factor correction (PFC) and upgrade power quality issues [5]. The novel approach to reduce the torque ripple in BLDC motor drive with SEPIC converter combined with three level neutral-point-clamped inverter has been developed which results better suppression of commutation torque ripple [6].

The torque ripple has been improved only by operating the three phase inverter fed BLDC motor drive in $180^{\circ}$ conduction mode instead of frequent $120^{\circ}$ conduction mode. The commutation torque ripple mainly happens due to switching of load current from one phase to another phase at every $60^{\circ}$ instant. The proposed approach uses dual switching mode technique to enhance the commutation torque ripple of the motor [7]. The new direct torque control for BLDC motor with upgraded reliability has been addressed to limit the torque ripple with the use of three level hysteresis torque controller [8]. The cost effective BLDC drive for water pump application has been designed. The first intend to develop the mapping algorithm to match the torque and speed of the motor in order to achieve better efficiency point. The second intend to develop the cost-effective BLDC motor for widespread numerical analysis technique [9]. The vector approach along with petal shape current trajectory operated PM BLDC motor drive to achieve ripple free torque has been presented. The proposed petal wave current supply improves the torque capability [10]. The torque ripple minimization technique for BLDC motor drive without a DC link capacitor has been developed which uses single switch control strategy, operation is similar to buck converter at any switching state and effective validation has been experimented with a $250 \mathrm{w}$ prototype motor drive, with effective compensation of torque ripple [11]. The analysis of sinusoidal versus square wave current supply for PM BLDC motor drive has been described. The square wave currents supplied to BLDC motor affects the torque performance when the motor operates at high speed and during commutation process the significant torque ripple ascends at both low and high speed ranges [12].

Torque predictive control (TPC) to minimize the torque ripple for PMSM motor drive has been designed which contains mathematical calculations to select the reference voltage vector which control the electromagnetic torque and stator flux with the estimated torque and stator flux errors which further tends to reduce the torque ripple and improved dynamics of the system [13, 14]. Inter turn short circuit fault analysis strategy to interior PMSM for electric vehicle application has been proposed [15]. The regenerative charging control strategy for BLDC motor drive applicable to advanced electric vehicle (EV) has been discussed. The Tagaki-Sugeno (T-S) fuzzy logic control technique has been presented to show the nonlinear dynamics [16]. The PWM technique apt for three phases SBI has been proposed and implemented in digital platform [17]. The established VSI generates output voltage always lesser than the dc input voltage. Hence the introduction of shoot through state in Z-source inverter (ZSI) can boost the inverter output voltage beyond the dc input voltage and triumph over these shortcoming of established VSI. More recently the developed Switched Boost Inverter (SBI) has been extended from single phase to three phases which boosts output voltage beyond the dc input voltage with reduced LC component count [18]. The RPWM technique has been proposed to BLDC motor to enhance the performance of the drive [19]. The space vector PWM approach has been proposed to minimize the torque ripple in BLDC motor [20]. The performance of speed and torque response has been estimated for BLDC motor using fuzzy logic and proportional integral (PI) controller. From the validation, Fuzzy logic controller provides better dynamic performance and limited errors, when subjected to load disturbance [21]. A 21 level multilevel inverter approach with new switching configuration has been proposed for BLDC motor drive. The proposed topology offer satisfied voltage profile with reduced switching devices and reduced torque ripple [22].

The meticulous literature analysis shows that improvement of torque quality in BLDC motor drive is being the motivated topic of many researchers. This paper discusses about the minimization of commutation 
torque ripple present in BLDC motor. The three phase SBI connected with BLDC motor drive offers appreciable torque ripple performance. The performance is studied in MATLAB/Simulink simulation platform and compared the results with experimental setup.

\section{PROPOSED TOPOLOGY OF THREE PHASE SBI BASED BLDC MOTOR DRIVE}

Figure 1 shows the provenience of torque ripple in permanent magnet machines, in which the proposed topology focuses on current commutation events. The proposed three phase switched boost mode incorporated in inverter fed BLDC motor pioneer shoot through mode during commutation interval with minimum passive component.

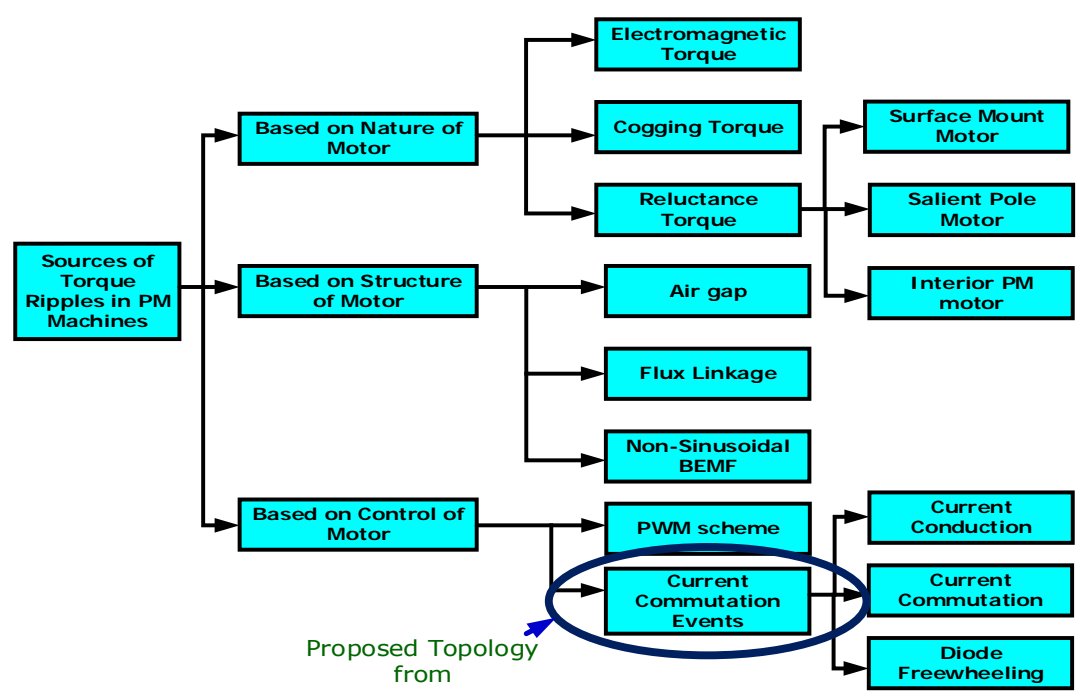

Figure 1. Torque ripple sources in PM machines

Figure 2 shows the three phase SBI based BLDC motor drive. Since the BLDC motor uses rotor position sensor, this is logically ANDed with the switching pattern of Switched boost inverter.

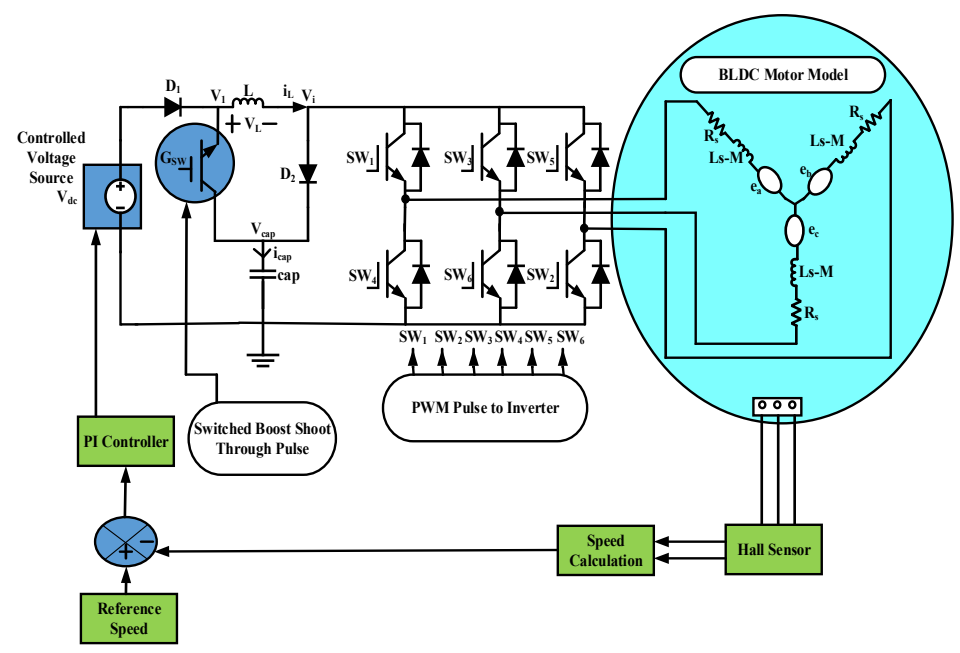

Figure 2. Three phase SBI based PMBLDCM drive 


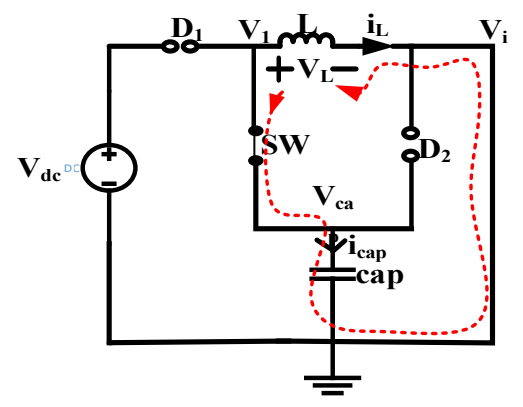

(a) Mode 1

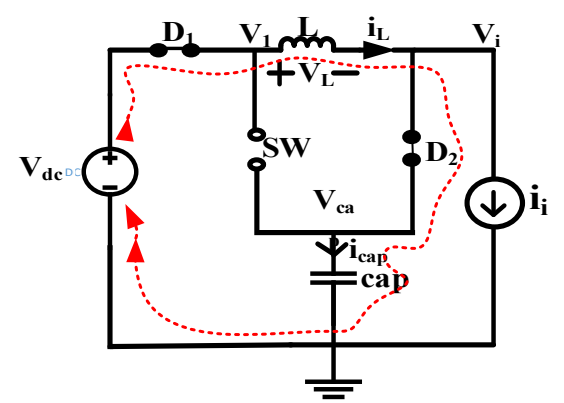

(b) Mode 2

Figure 3. (a) Equivalent circuit of SBI during switch ' $\mathrm{SW}$ ' $\mathrm{ON}$,

(b) Equivalent circuit of SBI during switch 'SW' OFF

The steady state operation of the boost inverter in mode 1 explains the inverter is in shoot through state for duration $t_{o n}$ in a switching cycle $T_{S}$. The switch $\mathrm{SW}$ is also turned on during this interval. In this mode the diodes $D_{1}$ and $D_{2}$ are reverse biased (as $V_{C a p}>V_{d c}$ ), and the capacitor $C$ charges the inductor $L$ through switch SW and the inverter bridge which is shown in Figure 3a. The mathematical equations governed by the inverter during mode 1 are given in (1).

$$
V_{L}=V_{\text {cap }} ; i_{\text {cap }}=-i_{L} ; V_{i}=0
$$

Figure $3 \mathrm{~b}$ represents the equivalent circuit of SBI during switch ' $\mathrm{SW}$ ' in OFF duration. During this duration, the switch SW is turned off and diode $\mathrm{D}_{1}$ and $\mathrm{D}_{2}$ are forward biased to offer path for the inductor current $i_{L}$. The mathematical equations governed by the inverter during mode 2 are given in (2).

$$
V_{L}=V_{d c}-V_{c a p} ; i_{c a p}=i_{L}-i_{1} ; V_{i}=V_{c a p}
$$

\section{PWM CONTROL STRATEGY OF THREE-PHASE SBI}

The Switching pattern for (GS, GS1, GS3, GS5, GS4, GS6, GS2) of the SBI has been explained in the Figure 3 it is not possible to directly adopt the PWM control strategy of VSI. The SBI uses extra switch 'SW' along with the six step three phase inverter. The introduction of shoot through state in SBI boosts the output voltage of the inverter. The switch ' $\mathrm{SW}$ ' should be harmonized with the shoot-through state of the inverter. In Figure $4 \mathrm{~V}_{\text {tri }}$ is the carrier signal with peak value of $\mathrm{V}_{\mathrm{p}} \mathrm{M}$ is Modulation index, $\mathrm{D}$ is duty ratio of shoot through state and $\mathrm{f}_{\mathrm{s}}$ is the switching frequency of switched boost inverter. Table 1 gives details about the generation of gate pulses for three phase SBI. Normally BLDC motor can be operated in $180^{\circ}$ and $120^{\circ}$ mode of operation. Here the SBI is operated in $180^{\circ}$ mode which means at any instant three switches are in conduction. During these instant two switches current enters to conduction and the third phase leaves to commutation (due to the loss of exact phase current control). Hence the possibility of torque ripple in BLDC motor tends to affect the performance of motor. At this instant shoot through region has been introduced to retain the third phase current in raising amplitude.

\begin{tabular}{|c|c|c|c|c|}
\hline \multirow{2}{*}{ Mode No. } & \multirow{2}{*}{ Duration } & \multicolumn{3}{|c|}{ Condition for gate control signal to be High } \\
\hline & & Gs1 & Gs3 & Gs4 \\
\hline 1 & $0^{\circ}-90^{\circ}$ & Vma $>$ Vtri & Vmb $>$ Vtri $>$ VST & Vmc $>$ Vtri \\
\hline 2 & $90^{\circ}-210^{\circ}$ & Vma $>$ Vtri & $\mathrm{Vmb}>\mathrm{Vtri}$ & Vmc $>$ Vtri $>$ VST \\
\hline 3 & $210^{\circ}-330^{\circ}$ & Vma $>$ Vtri $>$ VST & $\mathrm{Vmb}>\mathrm{Vtri}$ & $\mathrm{Vmc}>\mathrm{Vtri}$ \\
\hline 4 & $330^{\circ}-360^{\circ}$ & Vma $>$ Vtri & $\mathrm{Vmb}>\mathrm{Vtri}>\mathrm{VST}$ & $\mathrm{Vmc}>\mathrm{Vtri}$ \\
\hline \multirow{2}{*}{ Mode No. } & \multirow{2}{*}{ Duration } & \multicolumn{3}{|c|}{ Condition for gate control signal to be High } \\
\hline & & Gs4 & Gs6 & Gs2 \\
\hline 1 & $0^{\circ}-30^{\circ}$ & Vma $<$ Vtri & $\mathrm{Vmb}<\mathrm{VST}$ & Vmc $<$ Vtri $<-$ VST \\
\hline 2 & $30^{\circ}-150^{\circ}$ & $\mathrm{Vma}<\mathrm{Vtri}<-\mathrm{VST}$ & $\mathrm{Vmb}<\mathrm{Vtri}$ & $\mathrm{Vmc}<\mathrm{Vtri}$ \\
\hline 3 & $150^{\circ}-270^{\circ}$ & Vma $<$ Vtri & $\mathrm{Vmb}<\mathrm{Vtri}<-\mathrm{VST}$ & $\mathrm{Vmc}<$ Vtri \\
\hline 4 & $270^{\circ}-360^{\circ}$ & Vma $<$ Vtri & $\mathrm{Vmb}<\mathrm{Vtri}$ & Vmc $<$ Vtri $<$-VST \\
\hline
\end{tabular}

Table 1. Switching pattern for switches $\mathrm{S}_{1}, \mathrm{~S}_{3}, \mathrm{~S}_{5}, \mathrm{~S}_{4}, \mathrm{~S}_{6}, \mathrm{~S}_{2}$

Torque ripple minimization of PMBLDC motor using simple boost inverter (V. Krishnakumar) 


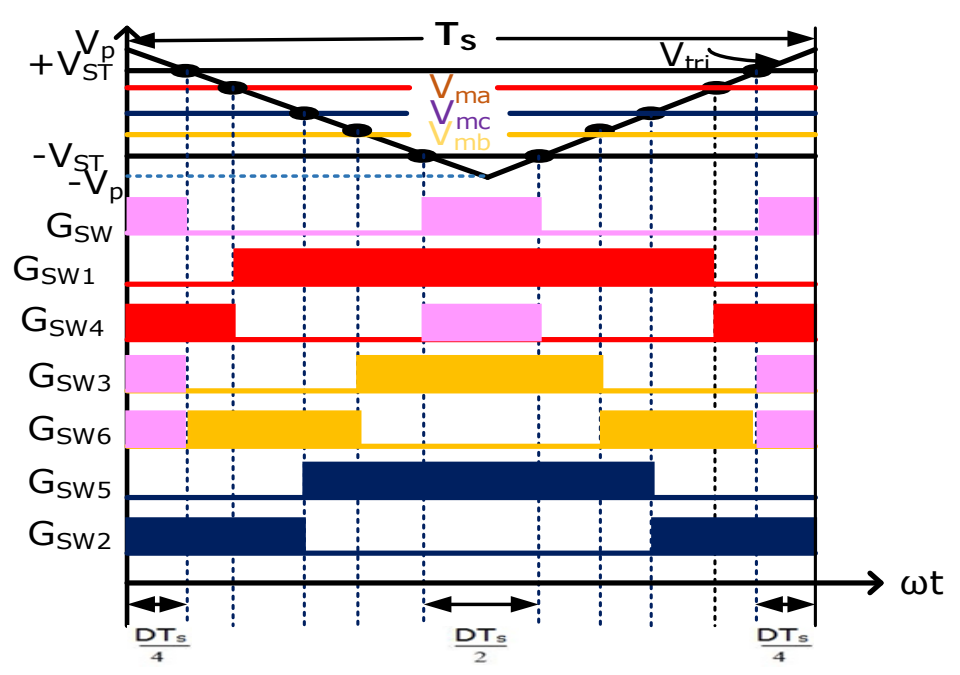

Figure 4. Switching pattern of SBI

\section{CURRENT BEHAVIOR DURING SWITCHING USING TRADITIONAL CONTROL}

The behavior of the current with different speeds is shown in Figure 5. There are three conclusions that can be drawn:

(1) If $\mathrm{Vdc}>2 \mathrm{Em}$, then $\mathrm{td}>\mathrm{tr}$, and the torque remains rising during commutation. The phase currents are shown in Figure 5(a).

(2) If $\mathrm{Vdc}<2 \mathrm{Em}$, then $\mathrm{td}<\mathrm{tr}$, and the torque remains declining during commutation. The currents in the three phases are shown in Figure 5(b).

(3) If $\mathrm{Vdc}=2 \mathrm{Em}$, then $\mathrm{td}=\mathrm{tr}$, and the torque is constant during commutation, which is the ideal case, where no torque ripple results, which is shown in Figure 5(c).

Considering these relation, this paper proposes a modified circuit topology, which standardizes the dc-link voltage remains to $2 \mathrm{Em}$ throughout the commutation interval. After proper validation, the current increasing and dropping speeds became equal; hence the torque ripple is suppressed.

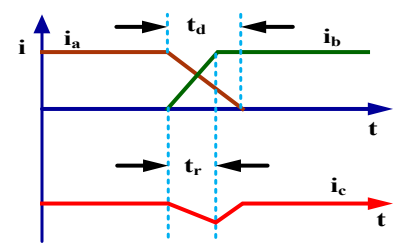

(a) $V_{d c}>2 E_{m}, t_{d}>t_{r}$

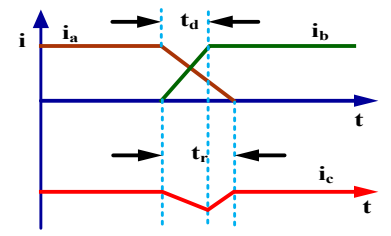

(b) $\mathrm{V}_{\mathrm{dc}}>2 \mathrm{E}_{\mathrm{m}}, \mathrm{t}_{\mathrm{d}}<\mathrm{t}_{\mathrm{r}}$

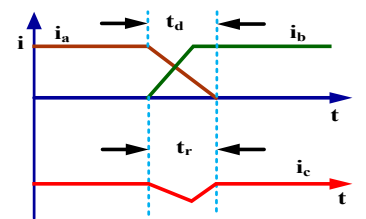

(c) $\mathrm{V}_{\mathrm{dc}}=2 \mathrm{E}_{\mathrm{m}}, \mathrm{t}_{\mathrm{d}}=\mathrm{t}_{\mathrm{r}}$

Figure 5 Current behaviors during switching

The time to reach for $i_{a}$ to become extinct from the primary value is expressed in

$t_{d}=\frac{3 L I_{m}}{V_{d c}+E_{m}}$

Where $\mathrm{V}_{\mathrm{dc}}$ is the dc-link voltage.

The time to reach for $i_{b}$ to increase from 0 to $I_{m}$ is

$t_{r}=\frac{3 L I_{m}}{\left(V_{d c}-E_{m}\right)}$ 


\section{SIMULATION RESULT}

To appraise the utilization of the proposed method, the SBI based BLDC motor drive shown in Figure 2 has been simulated using MATLAB/Simulink. The specification of the BLDC motor used for simulation has been given in Table 2. The torque and stator current waveforms of the simulated BLDC motor drive system using traditional PWM control method at $3000 \mathrm{rpm}$ and load torque of $2 \mathrm{NM}$ are shown in Figure $6 \mathrm{a}$ and $6 \mathrm{~b}$. Enlarged view of stator current for proposed SBI fed BLDC motor drive is shown in Figure 7. Torque response of proposed SBI fed BLDC motor drive is shown in Figure 8. Stepped input torque response of proposed SBI fed BLDC motor drive is shown in Figure 9. Speed response of proposed SBI fed BLDC motor for different speed ranges i) $750 \mathrm{rpm}$ ii) $3000 \mathrm{rpm}$ is shown in Figure 10. The percentage torque ripple for the traditional control is $50 \%$. The proposed SBI based BLDC motor drive was simulated, and the torque and stator current waveforms of the simulated results are shown in Figure $6 \mathrm{c}$ and $6 \mathrm{~d}$. The percentage torque ripple for the proposed method is $7 \%$.

Table 2. Motor specifications

\begin{tabular}{cc}
\hline Parameters & Values \\
\hline Stator phase resistance, Rs & $2.875 \mathrm{~m} \Omega$ \\
Stator phase inductance, Ls & $850 \mu \mathrm{H}$ \\
Pole pairs & 4 \\
DC supply voltage & $100 \mathrm{~V} \mathrm{DC}$ \\
Current limit threshold & $20 \mathrm{~A}$ \\
DC Bus Capacitance C1 and C2 & $200 \mathrm{Mf}$ \\
Inertia, viscous damping, static friction constants & $0.8 \mathrm{e}-3 \mathrm{~J}$ (kg.m2),1 e-3 F(N.m.s) \\
\hline
\end{tabular}
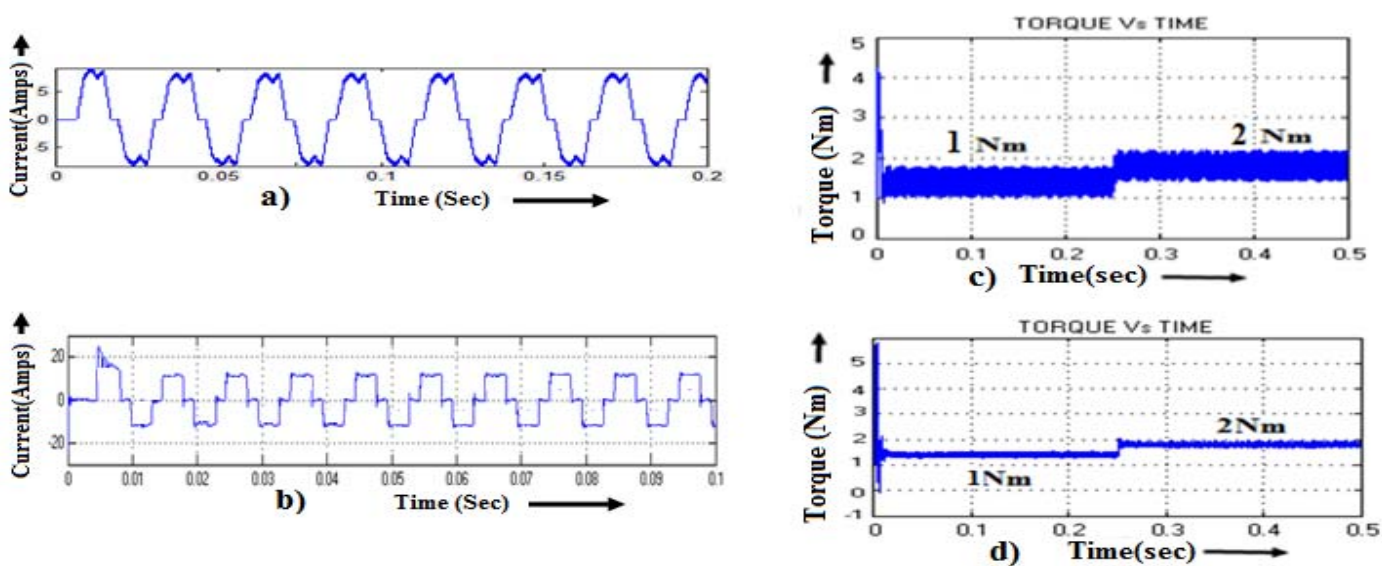

Figure 6. Simulation result of stator phase current and torque, (a) Current waveform from the existing control at $3000 \mathrm{rpm}$ and step torque of $2 \mathrm{Nm}$; (b) Current waveform from the proposed SBI topology at $3000 \mathrm{rpm}$ and step torque of $2 \mathrm{Nm}$; (c) Torque waveform from the existing control at $3000 \mathrm{rpm}$ and step torque $2 \mathrm{Nm}$; (d) Torque waveform from the proposed SBI topology at $3000 \mathrm{rpm}$ and step torque $2 \mathrm{Nm}$

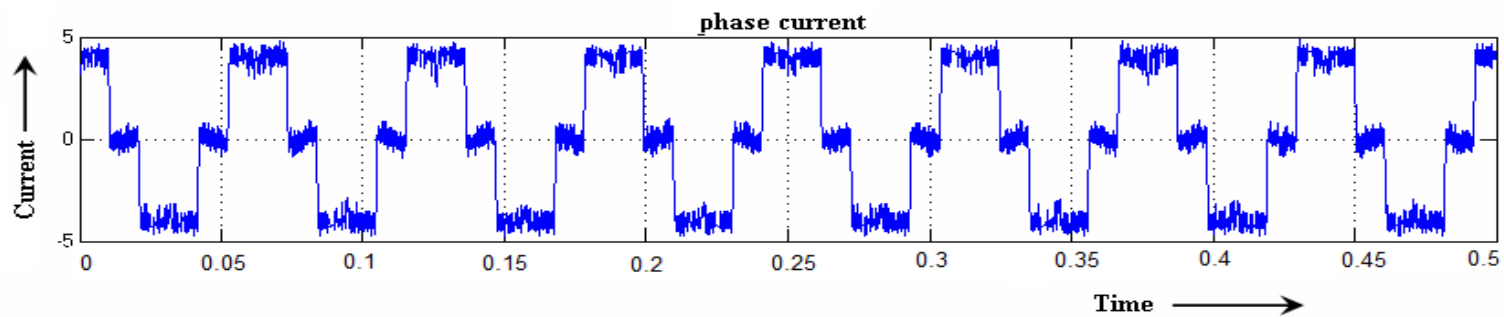

Figure 7. Enlarged view of stator current for proposed SBI fed BLDC motor drive 
Torque Vs Time

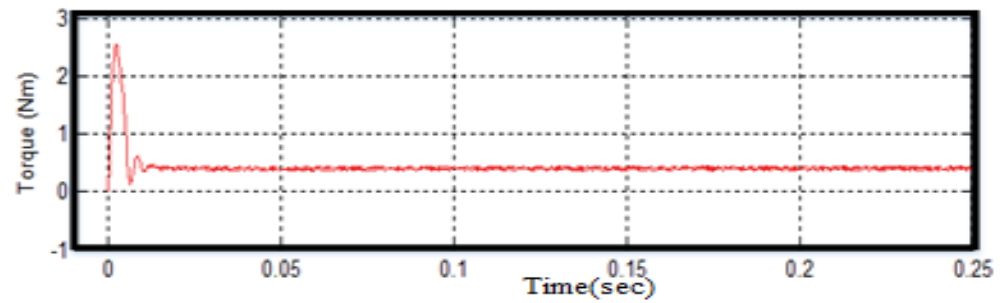

Figure 8. Torque response of proposed SBI fed BLDC motor drive

Torque VsTime (Step Input)

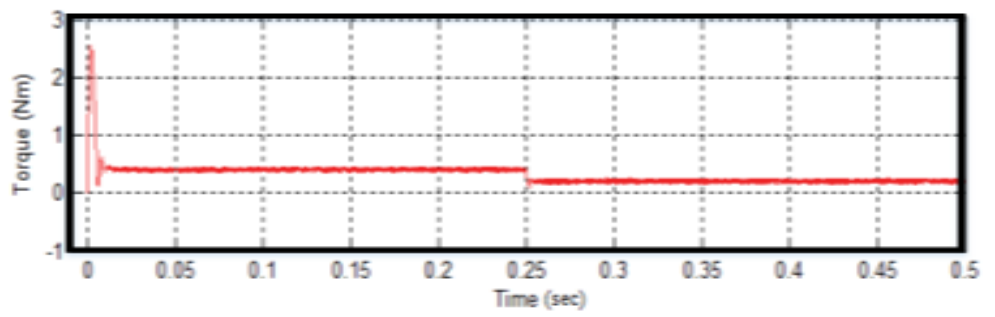

Figure 9. Stepped input torque response of proposed SBI fed BLDC motor drive

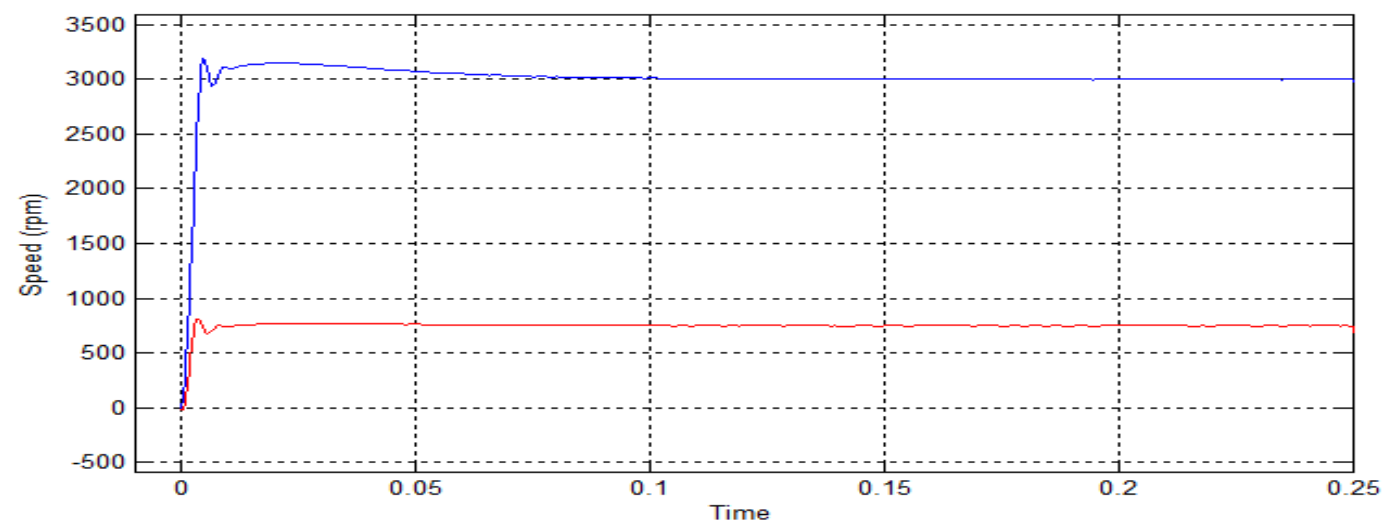

Figure 10. Speed response of proposed SBI fed BLDC motor for different speed ranges (i) $750 \mathrm{rpm}$; (ii) $3000 \mathrm{rpm}$.

\section{EXPERIMENTAL RESULT}

To validate the proposed SBI based BLDC motor performance, a Xilinx Spartan-III 3ANXC3S400controller is used. MATLAB-Xilinx System Generator tool is used for the implementation. The generated MATLAB-Simulink code is rehabilitated to bit file to access the FPGA board. In order to verify the proposed torque ripple limit strategy, the FPGA controller is programmed in processing unit and controlling unit.

The hall signal from the respective sensors and switching pattern of SBI are logically multiplied using AND gate to generate the corresponding switching pulse for three phase SBI in order to achieve better torque response during commutation interval.

Int J Pow Elec \& Dri Syst Vol. 10, No. 4, Dec 2019 : 1714 - 1723 


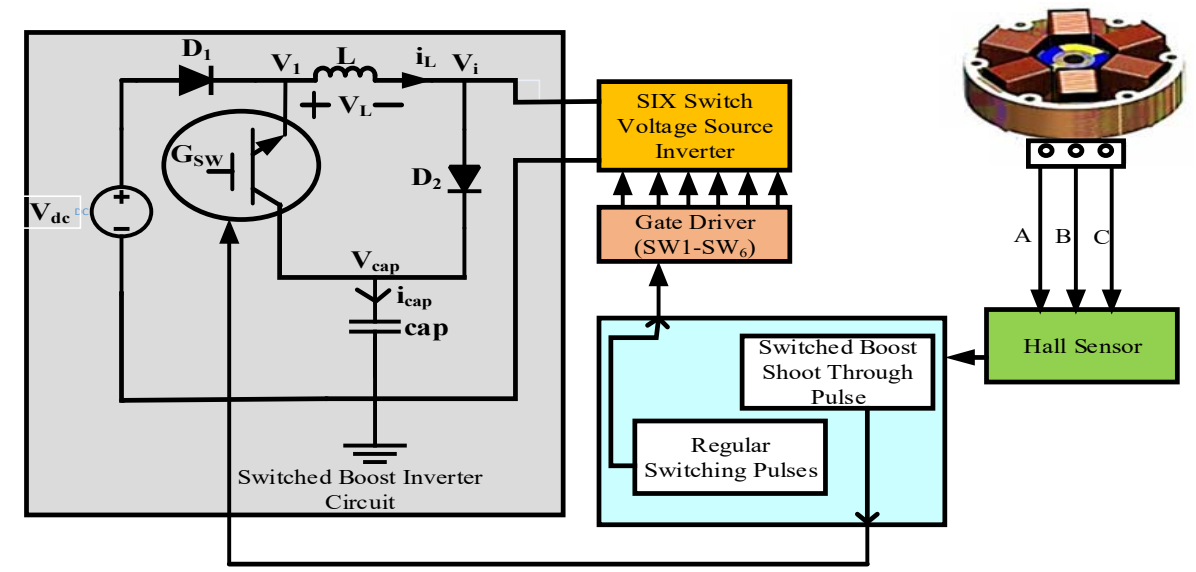

Figure 11 Experimental validation of SBI based BLDC motor drive

The effectiveness and viability of the proposed method has been validated by using real time experiments. The specification of BLDC motor is summarized in Table 2. The experimental set up of the controller used to generate the gate control pulses and BLDC motor are shown in Figure 11. The position of the rotor is sensed using Hall Effect sensors. The Switched boost circuit combined with three phase VSI are operated between 10 to $50 \mathrm{kHz}$ respectively. The experimental and simulation results evident the close match of proposed SBI based BLDC motor drive. Figure $12 \mathrm{a}$ and $\mathrm{b}$ represents the phase current response of proposed SBI topology with torque of $0.9 \mathrm{Nm}$. Figure $12 \mathrm{~b}$. represents the torque response of proposed SBI topology of torque 0.9 $\mathrm{Nm}$. The experimental result validates the torque ripple is reduced in the proposed SBI based BLDC motor drive and can capable to operate over a wide speed range. Figure 13 validates the essence of torque ripple minimization using proposed SBI based BLDC motor drive versus the other drive systems applicable from the literature. The torque ripple calculation of proposed SBI based BLDC motor is given below.

Torque ripple $=\frac{T_{\max }-T_{\min }}{T_{\text {average }}}=\frac{0.966-0.911}{0.88}=7 \%$

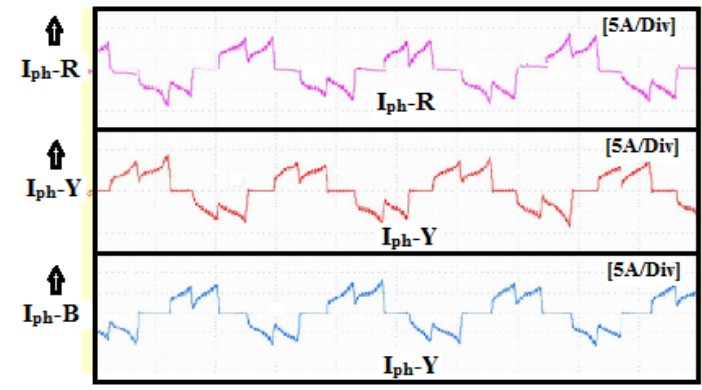

(a) Three phase current response of proposed SBI topology with torque of $0.9 \mathrm{Nm}$

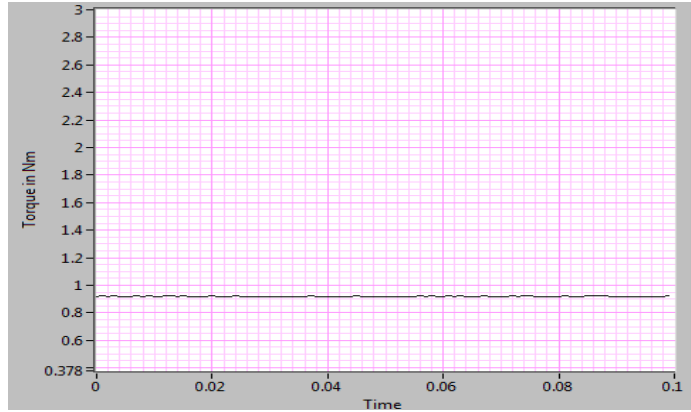

(b) Torque response of proposed SBI topology of torque $0.9 \mathrm{Nm}$

Figure 12. Experimental results of Stator phase current and torque 


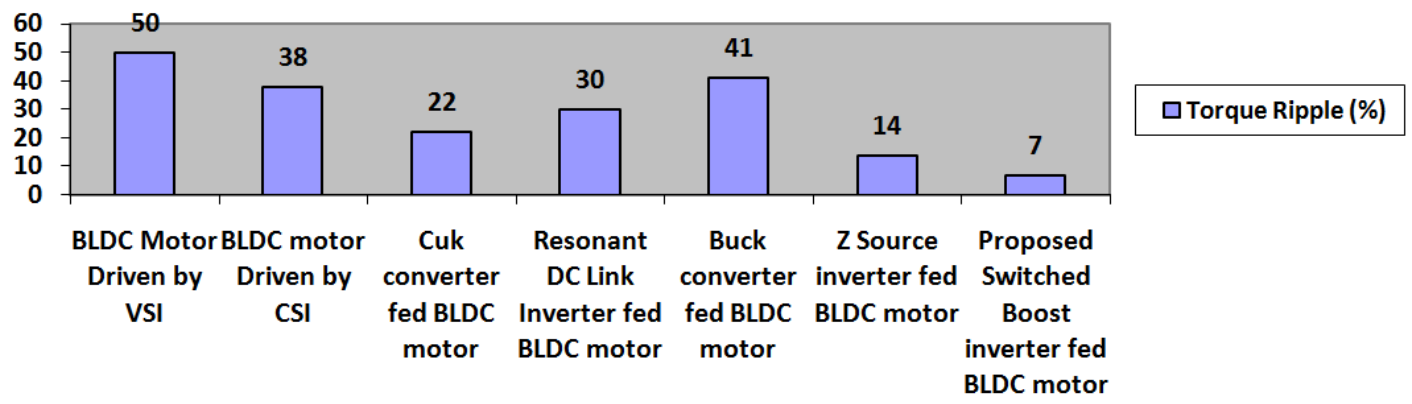

Figure 13 Various drive system versus torque ripple percentage

\section{CONCLUSION}

The SBI based BLDC motor is proposed that efficiently curtail the commutation torque ripple. The boost circuit has been connected to three phase inverter to regulate the dc link voltage and to curb the commutation torque ripple during switching (commutation interval). To validate the viability of the proposed system, the simulation and hardware setup were performed. Thus the results of the proposed system can effectively minimize the commutation torque ripple which in turn effectively used in medical laboratory applications. The comparison of torque ripple percentage with various drive system is performed, the SBI results better torque ripple minimization with reduced passive components than the other drive systems.

\section{REFERENCES}

[1] C. Sheeba Joice, S. R. Paranjothi, and V. Jawahar Senthil Kumar, "Digital Control Strategy for Four Quadrant Operation of Three Phase BLDC Motor with Load Variations," IEEE Transactions on Industrial Informatics, vol. 9, no. 2, pp. 974-982, May 2013.

[2] Changliang Xia, Youwen Xiao, Wei Chen, and Tingna Shi, "Torque Ripple Reduction in Brushless DC Drives Based on Reference Current Optimization using Integral Variable Structure Control," IEEE Transactions on Industrial Electronics, vol. 61, no. 2, pp. 738-752, February 2014.

[3] Tae-Won Chun, Quang-Vinh Tran, Hong-Hee Lee, and Heung-Geun Kim, "Sensorless Control of BLDC Motor Drive for an Automotive Fuel Pump using a Hysteresis Comparator," IEEE Transactions on Power Electronics, vol. 29, no. 3, pp. 1382-1391, March 2014.

[4] K. J. Kang, G. H. Jang, and S. J. Sung, "Frequency Characteristics of BEMF, Cogging Torque and UMF in a HDD Spindle Motor due to Unevenly Magnetized PM," IEEE Transactions on Magnetics, vol. 49, no. 6, pp. 2578-2581, June 2013.

[5] Vashist Bist and Bhim Singh, "A Reduced Sensor PFC BL-Zeta Converter based VSI Fed BLDC Motor Drive," Elsevier Electric Power Systems Research, vol. 98, pp. 11-18, February 2013.

[6] V. Viswanathan and S. Jeevananthan, "Approach for Torque Ripple Reduction for Brushless DC Motor based on Three-Level Neutral-Point-Clamped Inverter with DC-DC Converter," IET Power Electronics, vol. 8, no. 1, pp. 47-55, 2015.

[7] S. S. Bharatkar, Raju Yanamshetti, D. Chatterjee, and A. K. Ganguli, "Commutation Torque Ripple Analysis and Reduction Through Hybrid Switching for BLDC Motor Drives," Proceedings of IEEE Region 10 and the Third International Conference on Industrial and Information Systems (ICIIS'08), Kharagpur, pp. 1-5, 2008.

[8] Mourad Masmoudi, Bassem El Badsi, and Ahmed Masmoudi, "DTC of B4-Inverter-Fed BLDC Motor Drives with Reduced Torque Ripple during Sector-to-Sector Commutations," IEEE Transactions on power electronics, vol. 29, no. 9, pp. 4855-4865, September 2014.

[9] Mohamed Z. and Youssef, "Design and Performance of a Cost-Effective BLDC Drive for Water Pump Application," IEEE Transactions on Industrial Electronics, vol. 62, no. 5, pp. 3277-3284, May 2015.

[10] Giuseppe Buja, Manuele Bertoluzzo and Ritesh Kumar Keshri, "Torque Ripple-Free Operation of PM BLDC Drives with Petal-Wave Current Supply," IEEE Transactions on Industrial Electronics, vol. 62, no. 7, pp. 40344043, July 2015.

[11] H. K. Samitha Ransara and Udaya K., Madawala, "A Torque Ripple Compensation Technique for a Low-Cost Brushless DC Motor Drive," IEEE Transactions on Industrial Electronics, vol. 62, no.10, pp. 6171-6182, October 2015.

[12] Manuele Bertoluzzo, Giuseppe Buja, Ritesh Kumar Keshri, and Roberto Menis, "Sinusoidal Versus Square-Wave Current Supply of PM Brushless DC Drives: A Convenience Analysis," IEEE Transactions on Industrial Electronics, vol. 62, no. 12, pp. 7339-7348, December 2015.

[13] Hao zhu, Xi Xiao and Yongdong Li, "Torque Ripple Reduction of the Torque Predictive Control Scheme for Permanent-Magnet Synchronous Motors," IEEE Transactions on Industrial Electronics, vol. 59, no. 2, pp. 871877, February 2012.

Int J Pow Elec \& Dri Syst Vol. 10, No. 4, Dec 2019 : 1714 - 1723 
[14] Yongsoo Cho, Kyo-Beum Lee, Joong-Ho Song and Young Lee, "Torque-ripple minimization and fast dynamic scheme for torque predictive control of permanent-magnet synchronous motors," IEEE Transactions on Power Electronics, vol. 30, no. 4, pp. 2182-2190, April 2015.

[15] Bochao Du, Shaopeng Wu, Shouliang Han and Shumei Cui, "Application of Linear Active Disturbance Rejection Controller for Sensorless Control of Internal Permanent-Magnet Synchronous Motor," IEEE Transactions on Industrial Electronics, vol. 63, no. 5, pp. 3019-3027, 2016.

[16] Xizheng Zhang, Yaonan Wang, Guorong Liu and Xiaofang Yuan, "Robust Regenerative Charging Control Based on T-S Fuzzy Sliding-Mode Approach for Advanced Electric Vehicle," IEEE Transactions on Transportation Electrification, vol. 2, no. 1, pp. 52-65, March 2016.

[17] Ravindranath Adda, Avinash Joshi and Santanu Mishra, "Pulse Width Modulation of Three-Phase Switched Boost Inverter," Proceeding of IEEE-Energy Conversion Congress and Exposition (ECCE'2013), pp.769-774, September 15-19, 2013.

[18] Adda Ravindranath, Santanu K., Mishra, and Avinash Joshi, “Analysis and PWM Control of Switched Boost Inverter," IEEE Transactions on Industrial Electronics, vol. 60, no. 12, pp. 5593-5602, 2013.

[19] V. Krishnakumar, V. Kamaraj and S. Jeevananthan, "Performance Improvement of Multilevel Inverter Fed Brushless DC Motor Using Random Pulse Width Modulation Technique," Australian Journal of basic and Applied Sciences, vol. 9, no. 16(Special Issue), pp.162-171, 2015.

[20] C. Bharatiraja, S. Babu, V. Krishnakumar, P. Sanjeevikumar, N. George, "Investigation of slim type BLDC motor Drive with torque ripple minimization using abridged space-vector PWM control method," International Journal of Power Electronics and Drive Systems, vol. 8, no. 2, pp. 593-600, 2017.

[21] Akram H. Ahmed, Abd El Samie B. Kotb and Ayman M.Ali, "Comparison between Fuzzy Logic and PI Control for the Speed of BLDC Motor," International Journal of Power Electronics and Drive System (IJPEDS), vol. 9, no. 3, pp. 1116-1123, 2018.

[22] J. Srinivas Rao, P. Srinivasa Varma and T. Suresh Kumar, "Novel Switching Design Structure for Three Phase 21-Level Multilevel Inverter Fed BLDC Drive Application," International Journal of Power Electronics and Drive System (IJPEDS), vol. 9, no. 3, pp. 1202-1213, 2018. 